\title{
MECHANISM OF POLYMERIZATION OF PROTEINS BY AUTOXIDIZED PRODUCTS OF LINOLEIC ACID ${ }^{1}$
}

\author{
P. T. Gamage, Tomohiko Mori, and Setsuro Matsushita ${ }^{2}$ \\ Research Institute for Food Science, Kyoto University, Kyoto
}

(Received February 28, 1973)

\begin{abstract}
Pure linoleic acid hydroperoxides and their secondary degraded products have been used as radical and non-radical products of oxidized lipids to determine the mechanism of polymerization of proteins by oxidized lipids. The radical reaction effecting polymerization of proteins was found to be specific with proteins and the mechanism of polymerization involves the initiation of protein radical formation by hydroperoxides which in turn interacts to form polymers. The polymerization of proteins by the non-radical products may be attributed to the intermolecular carbonylamine cross-linking reaction.
\end{abstract}

Proteins are known to form complexes with lipids, many of which are easily broken by non-polar solvents (1). Peroxidized lipids have been shown to form rather stable complexes with proteins (2). Autoxidized lipid-protein interactions feature the ultimate formation of insoluble lipid-protein complexes which are polymeric in nature (3). The polymerization depends upon the nature of both the lipid and protein and the $\mathrm{pH}$ of the reaction medium (4).

The proposed mechanism of polymerization of proteins by the autoxidized lipids is rather contradictory. DESAI (5) has suggested that the protein polymers are formed by cross-linking of proteins of the POOLOOP type $(\mathrm{P}=$ protein, $\mathrm{L}=$ lipid) by the peroxy radical addition reaction. RoubAL (3) has shown that soluble polymers are formed by the cross-linking of proteins without incorporating lipids of the $\mathrm{P}-(\mathrm{P})_{n}-\mathrm{P}$ type. Andrews (6), ShIN (7) and Chio (8) have shown that malonaldehyde, one of the terminal products of lipid oxidation, forms intra- and inter-molecular cross-linked products with proteins via a Schiff's base type reaction mechanism. No generalized rule can be drawn for the mechanism of polymerization as the reactivity of the oxidized products of lipids differs with proteins (9). Further, by using lipid-protein peroxidizing systems it becomes

1 Abbreviations: LAHPO, linoleic acid hydroperoxides; SP, secondary degraded products; BHT, butylated hydroxytoluene; AsA, ascorbic acid; TLC, thin-layer chromatography; SDS, sodium dodecyl sulphate; BSA, bovine serum albumin; POV, peroxide value.

2 森 友彦, 松下雪郎 
difficult to predict which component of oxidized lipid is involved in the protein polymerization. As shown by SHIN (7), the aldehyde reaction is a concentrationdependent and time consuming reaction, but the reaction involving free radical intermediates is expected to take place in considerably short time. The conditions of long-time reaction may degrade the radical intermediates to their SP and the observed results may be due to these SP or a combination of both LAHPO and SP.

Thus we have undertaken this investigation to clarify the role of the peroxidized radical intermediates and the non-radical products in polymerization of proteins, using purified LAHPO (free radical source) and SP (non-radical products) against 3 enzyme proteins. The conditions employed are comparatively mild though more drastic than the conditions used in our earlier study (enzyme inhibition by LAHPO or SP), because it was observed that the polymerization reaction under such conditions was too low as to be detected within the experimental limits of this study. The conclusions are drawn on short-reaction-time results. The involvement of the radical intermediates and the non-radical products of the oxidized lipids in the protein polymerization are discussed with respect to the mechanism of polymerization.

\section{MATERIALS AND METHODS}

Materials. Linoleic acid was purchased from Tokyo Kasei Co. and was used without further purification. Linoleic acid $1-{ }^{14} \mathrm{C}$ (specific activity, $35 \mathrm{mCi} / \mathrm{mmole}$ ) was obtained from Daiichi Chemical Co. Bovine pancreatic RNase (5x-crystallized), bovine pancreatic trypsin (2x-crystallized) and hog pepsin (2x-crystallized) were purchased from Sigma Chemical Co.

Preparation of autoxidized products of linoleic acid. Linoleic acid (2 g) was autoxidized at $37^{\circ} \mathrm{C}$ for $70 \mathrm{hr}$ and the autoxidized mixture was subjected to silica gel column chromatography as described in our earlier paper (10). The LAHPO fraction was further purified by preparative TLC using $n$-hexane: diethyl ether: acetic acid (60:40:1) as the solvent system. The hydroperoxide band (detected by UV light) was peeled off and extracted with methanol. The purity of the LAHPO was confirmed by TLC on silica gel plates, Merck $F_{254}$, using the same solvent system described above. The concentration of the LAHPO was determined by UV absorption at $233 \mathrm{~m} \mu$ using an extinction coefficient 25.25 (11).

The SP fraction (ether elute from the column) had a considerable POV. In all our determinations, the SP fraction was further oxidized until no more POV could be detected. The SP was dissolved in methanol and the concentration was expressed as carbonyls determined by the method of HeNICK (12).

In the preparation of labelled oxidized products of linoleic acid, $0.2 \mathrm{mCi}$ of $1-{ }^{14} \mathrm{C}$-linoleic acid was added to $2 \mathrm{~g}$ of cold linoleic acid and was autoxidized at $37^{\circ} \mathrm{C}$ for $70 \mathrm{hr}$. The preparation, purification and the determination of the 
labelled oxidized products followed the earlier procedure (10).

Incubation of LAHPO and SP with enzyme proteins. RNase (2-10 $\mathrm{mg})$ was dissolved in $0.5-1 \mathrm{ml}$ of $0.05 \mathrm{M}$ sodium acetate buffer, $\mathrm{pH} 5.0$ and LAHPO or SP in appropriate concentration was added and the mixtures were incubated at $37^{\circ} \mathrm{C}$. At specific intervals suitable aliquots were withdrawn and the free, bound or associated oxidized products were eliminated by extracting 5 times with ether.

Pepsin or trypsin was incubated with the oxidized products and was treated as in the case of RNase.

The effects of AsA or BHT on the interaction of LAHPO with RNase were determined by the addition of the reagents to the protein solution in appropriate concentrations before the addition of LAHPO.

Polyacrylamide gel electrophoresis. Samples for electrophoresis were dissolved in $0.1 \mathrm{M}$ sodium phosphate buffer, $\mathrm{pH} 7.0$ containing $1 \%$ SDS as described by SHIN (7). Samples were applied directly to the top of $10 \%$ gels $(10 \times 0.7 \mathrm{~cm})$ containing $0.1 \%$ SDS and was run for $5 \mathrm{hr}$ in the case of RNase and trypsin and $7 \mathrm{hr}$ for pepsin after pre-running the gels for $40 \mathrm{~min}$ to remove persulphates. The gels were stained in $0.05 \%$ coomassie blue containing $9 \%$ methanol and $7 \%$ acetic acid and were destained by boiling with $7 \%$ acetic acid. The standard proteins used for the determination of the molecular size of the polymerized products were RNase, trypsin, pepsin and BSA.

Fractionation of the polymerized products of RNase by Sephadex column chromatography. RNase $(10 \mathrm{mg})$ was incubated with an appropriate concentration of the labelled oxidized products as described earlier. The reacted proteins were devoided of free, bound or associated oxidized products by ether extraction followed by solubilization in $3 \mathrm{~m}$ urea. The insolubilized products were precipitated by centrifugation and were dissolved in $0.1 \mathrm{M}$ Tris buffer, $\mathrm{pH} 8$ or $10^{-3} \mathrm{M} \mathrm{HCl}$. The soluble fraction was chromatographed on a $110 \times 1.5 \mathrm{~cm}$ column of Sephadex G-100 using $0.1 \mathrm{~m}$ sodium acetate- $0.2 \mathrm{~m}$ sodium chloride, $\mathrm{pH} 6$ as the eluent as described by CHIO (8) at a flow rate of $8 \mathrm{ml} / \mathrm{hr}$. Four $\mathrm{ml}$ fractions were collected. The molecular size of the polymeric products were determined by the method of WhITAKeR (13) using RNase, trypsin, pepsin and BSA as standard proteins. The Lowry method (14) for measuring proteins was monitered at $750 \mathrm{~m} \mu$. To determine the incorporation of LAHPO or SP into the soluble reaction products, the radioactivity of the effluent fractions was determined in a liquid scintillation counter. The rate of insolubilization was determined by comparing the amount of proteins insolubilized after $3 \mathrm{~m}$ urea treatment to the amount solubilized by the oxidized products.

Fluorescence measurement. Equivalent concentrations of the oxidized products as used in the Sephadex column chromatographic determinations were added to $10 \mathrm{mg} / \mathrm{ml}$ of protein solutions and were incubated at $37^{\circ} \mathrm{C}$. The effects of AsA and BHT on the production of fluorescent products of RNase by the oxidized products were determined by the addition of the reagents into the protein 
solutions before the addition of the oxidized products in a final concentration of $0.05 \mathrm{M}$. At specific intervals suitable aliquots were withdrawn, washed with ether and solubilized in $0.1 \mathrm{~N} \mathrm{NaOH}$ in the case of RNase or trypsin and $0.1 \mathrm{M}$ sodium acetate buffer, $\mathrm{pH} 5$ in the case of pepsin. The fluorescence excitation and emission spectra of the samples were recorded in a Hitachi fluorescence spectrophotometer (MPF-2).

\section{RESULTS}

Polymerization of RNase can be simply demonstrated by polyacrylamide gel electrophoresis. Figure 1 shows the RNase polymers formed by LAHPO or SP. LAHPO formed a small amount of polymeric products even at $1 \mathrm{hr}$ incubation. At $2 \mathrm{hr}$ incubation, most of the RNase was dimerized with a slight formation of higher polymeric products. Four hr incubation showed at least 3 polymeric products. No significant formation of polymeric products of RNase was observed with SP up to $2 \mathrm{hr}$ incubation, but $4 \mathrm{hr}$ incubation resulted in $48 \%$ insolubilization. The neutral buffer solubilized fraction showed considerable amount of dimers.

Incubation of pepsin with the oxidized products under the conditions as used in the case of RNase up to $20 \mathrm{hr}$ incubation did not show a significant forma-

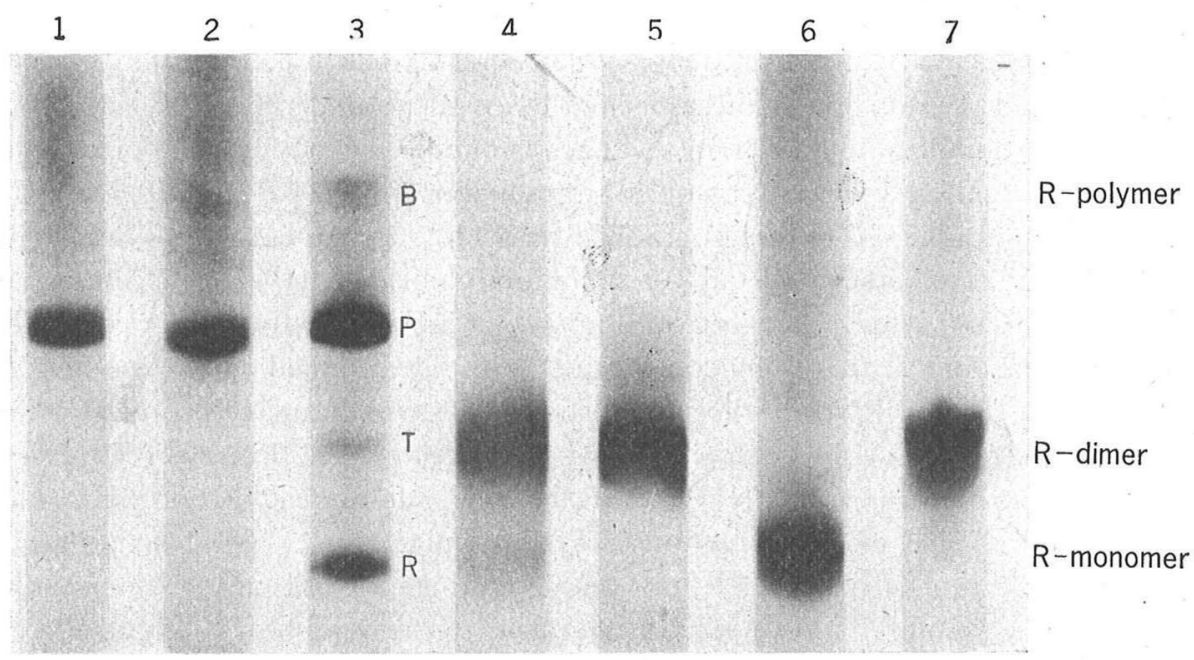

Fig. 1. Acrylamide gel electrophoretic patterns of RNase reacting with LAHPO or SP and pepsin. Proteins amounting to $200 \mu \mathrm{g}$ taken from the samples used in the Sephadex gel filtration (Figs. 2 and 3) were used. In the standard protein mixture, $50 \mu \mathrm{g}$ of RNase, trypsin, pepsin and BSA were used under the same conditions as in the reacted RNase. 1. Pepsin +SP $(20 \mathrm{hr})$; 2. pepsin + LAHPO $(20 \mathrm{hr})$; 3. standard protein mixture, $\mathrm{R}=\mathrm{RNase}, \mathrm{T}=$ trypsin, $\mathrm{P}=$ pepsin, $\mathrm{B}=\mathrm{BSA}$; 4. RNase + LAHPO $(2 \mathrm{hr})$; 5. RNase + LAHPO (4 hr); 6. RNase + SP ( $2 \mathrm{hr}) ; 7$. RNase + SP (4 hr). 


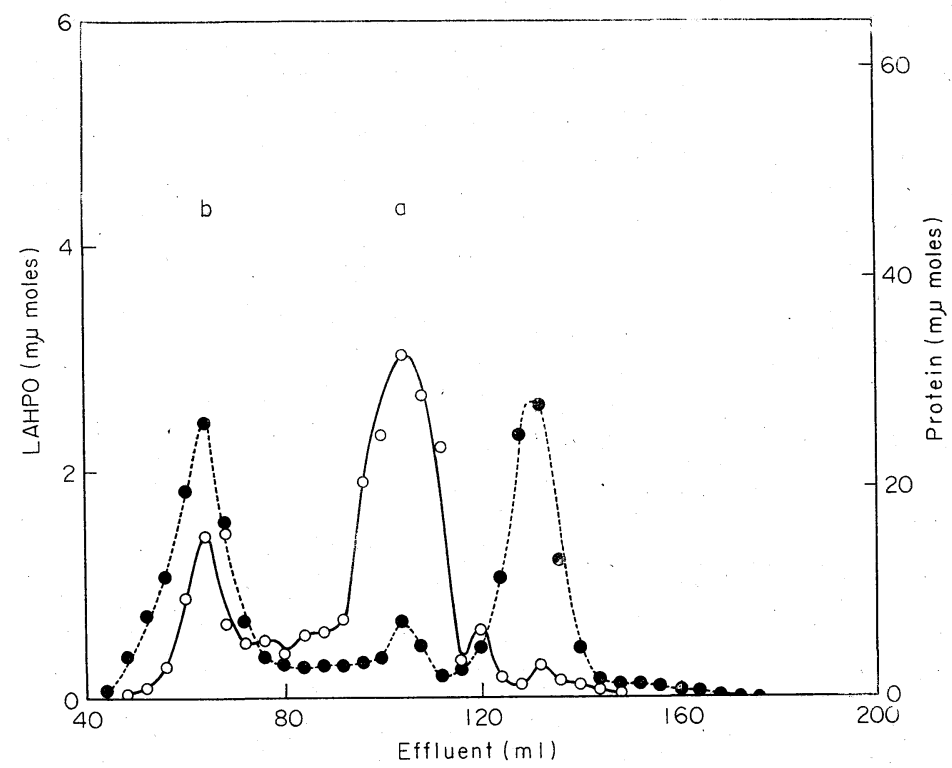

Fig. 2. Sephadex gel filtration of the LAHPO reacted RNase. RNase $(10 \mathrm{mg})$ in $0,5 \mathrm{ml}$ of $0.05 \mathrm{M}$ sodium acetate buffer, pH 5.0 was incubated with $10 \mathrm{mmoles}$ of $1-{ }^{14} \mathrm{C}$-LAHPO at $37^{\circ} \mathrm{C}$ for $4 \mathrm{hr}$. Four $\mathrm{ml}$ fractions were collected. An aliquote of the effluent fractions $(0.5 \mathrm{ml})$ was taken for radioactive assay. The rest was subjected to protein determination. $\mathrm{O} \bigcirc$, protein concentration; ---- , radioactivity.

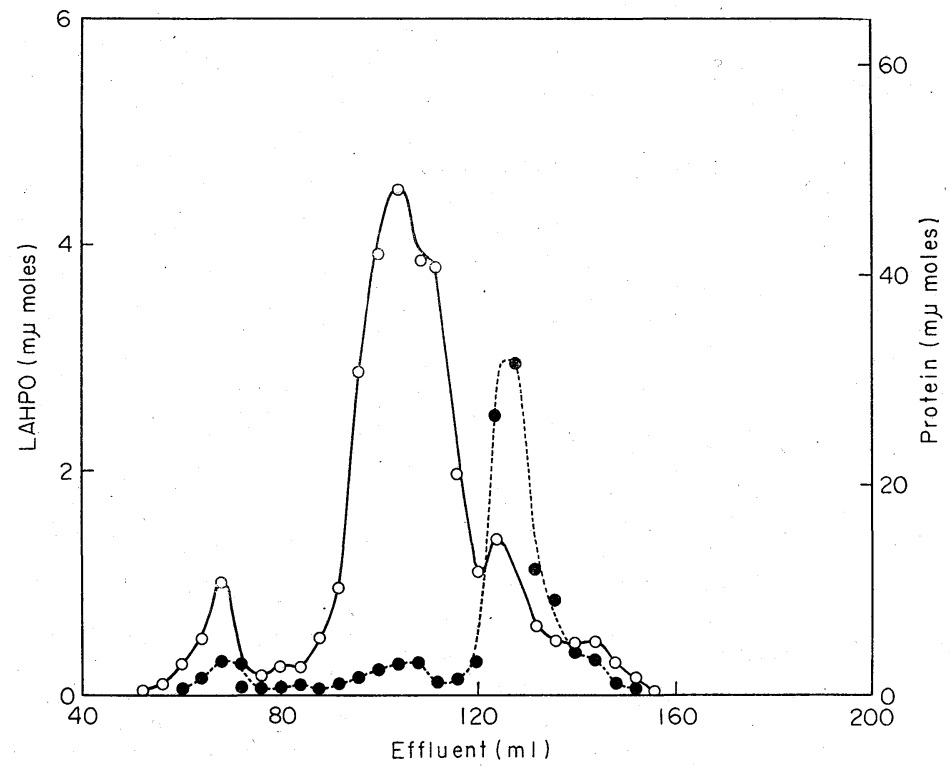

Fig. 3. Sephadex gel filtration of the RNase reacting with SP. RNase $(10 \mathrm{mg})$ in $0.5 \mathrm{ml}$ of $0.05 \mathrm{M}$ sodium acetate buffer, $\mathrm{pH} 5.0$ was incubated with 5.4 mmole of labelled SP at $37^{\circ} \mathrm{C}$ for $4 \mathrm{hr}$. The determinations and the presentations are as in Fig. 1 . 


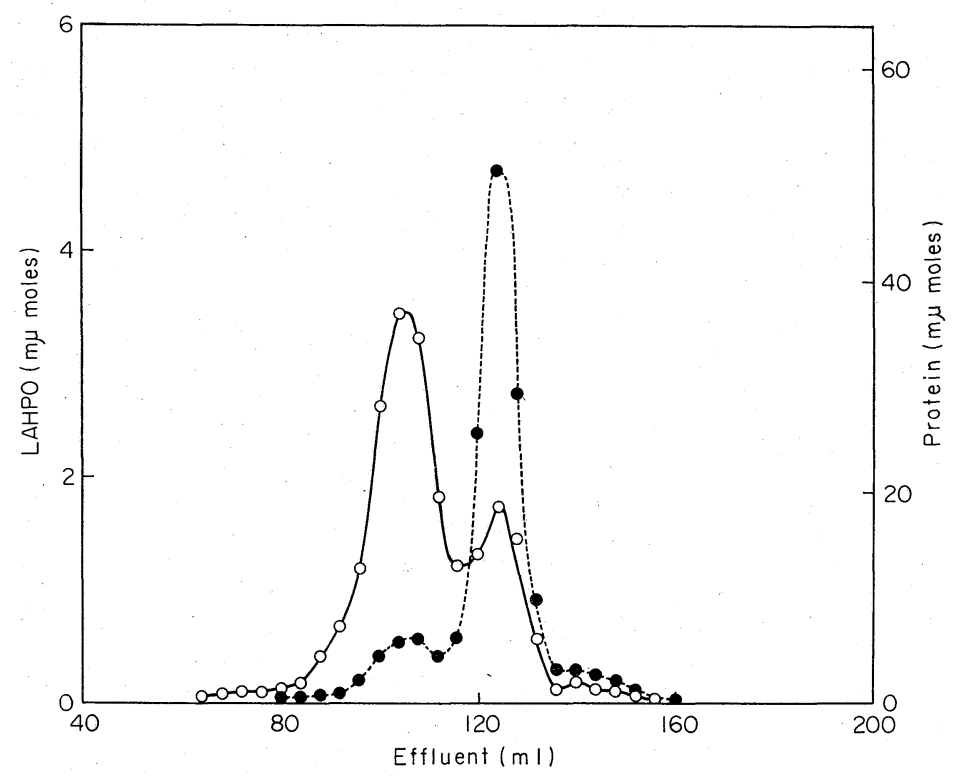

Fig. 4. The effect of AsA on the polymerization of RNase by LAHPO as determined by Sephadex gel chromatography. RNase $(10 \mathrm{mg})$ in $0.5 \mathrm{ml}$ of $0.05 \mathrm{M}$ sodium acetate buffer, pH 5.0 was incubated with 10 mmoles of $1-{ }^{14} \mathrm{C}-\mathrm{LAHPO}$ in the presence of 50 mmoles of AsA at $37^{\circ} \mathrm{C}$ for $2 \mathrm{hr}$. The determinations and the presentations are as in Fig. 1.

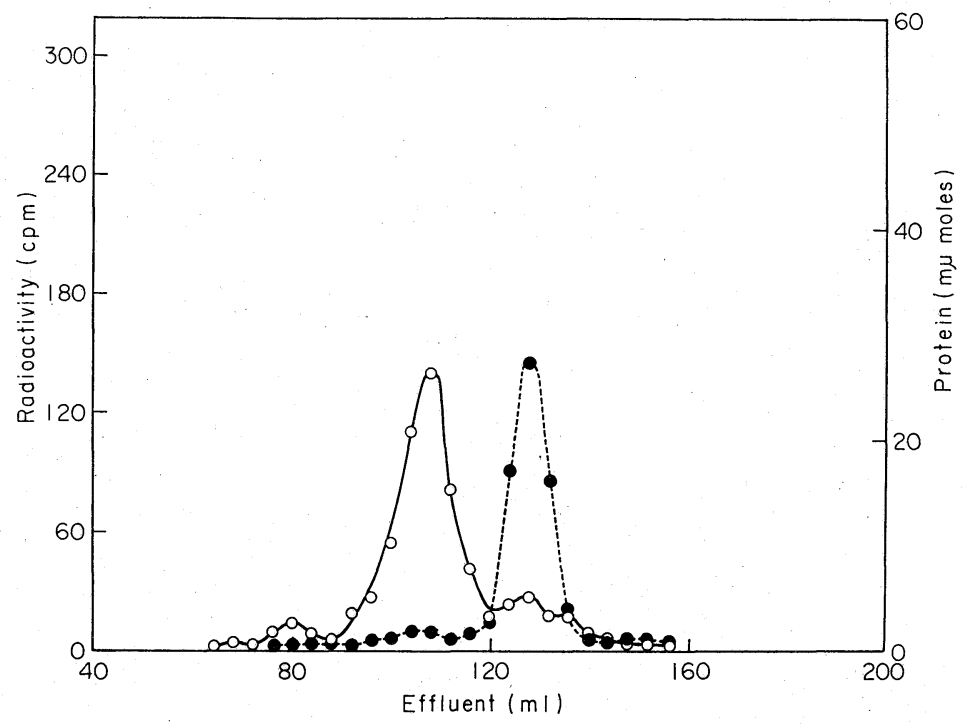

Fig. 5. The effect of BHT on the polymerization of RNase by LAHPO as determined by Sephadex gel chromatography. RNase $(10 \mathrm{mg})$ in $0.5 \mathrm{ml}$ of $0.05 \mathrm{M}$ sodium acetate buffer, $\mathrm{pH} 5.0$ was incubated with 10 mmoles of $1{ }^{14} \mathrm{C}$-LAHPO in the presence of 50 mmoles of BHT at $37^{\circ} \mathrm{C}$ for $4 \mathrm{hr}$. The determinations and the presentations are as in Fig. 1. 
tion of polymeric products as determined by gel electrophoresis (Fig. 1). Autocatalysis of trypsin under the conditions used prevented the determination. The autocatalized products were seen at the lower region of the gel.

The polyacrylamide gel electrophoretic pattern of RNase that reacted with LAHPO or SP is in good agreement with the elution pattern on the Sephadex column. RNase that has interacted with LAHPO was shown to contain at least 2 polymeric products (Fig. 2), while the RNase (soluble fraction) that reacted with SP was shown to contain only one polymeric product (Fig. 3). The mole ratio of LAHPO/protein association are 0.001 for peak a and 0.025 for peak $b$ (Fig. 2). As shown in Fig. 3, only a negligible amount of radioactivity is incorporated into RNase reacting with SP. When AsA is present in the reaction mixture, 1.7 times the amount of polymeric products of RNase are formed by LAHPO in a 2-hr incubation (Fig. 4) compared to a 4-hr incubation without AsA (Fig. 2). The radioactivity associated with the eluted peaks was much less in the presence of AsA than in the absence of AsA. Gel electrophoresis showed a broad band in the position corresponds to a RNase dimer. In contrast, BHT resulted in the reduction of the number of polymeric products formed (Fig. 5).

Incubating RNase with SP for $4 \mathrm{hr}$ resulted in the formation of products

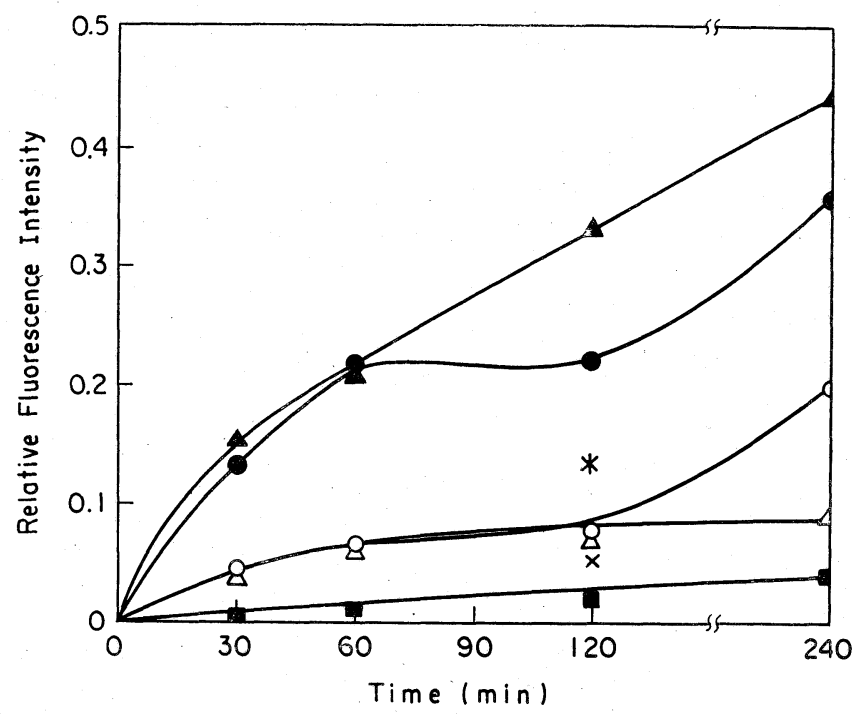

Fig. 6. The relative production of fluorescence in RNase, trypsin and pepsin by LAHPO or SP. RNase or pepsin $(10 \mathrm{mg})$ in $0.5 \mathrm{ml}$ of $0.05 \mathrm{M}$ sodium acetate buffer, $\mathrm{pH} 5.0$ or trypsin $(10 \mathrm{mg})$ in $0.5 \mathrm{ml}$ of $0.1 \mathrm{M}$ Tris buffer, $\mathrm{pH} 8.0$ was incubated with 10 mmoles of LAHPO or 5.4 mmoles of SP at $37^{\circ} \mathrm{C}$. - - RNase reacting with SP; $\bigcirc-\mathrm{O}, \mathrm{RNase}$ reacting with LAHPO; $\Delta-\Delta$, trypsin reacting with SP; $\triangle-\triangle$, trypsin reacting with LAHPO; - - , pepsin reacting with SP or LAHPO; $*$, RNase reacting with LAHPO with AsA; $\times$, RNase reacting with LAHPO with BHT. 
which have fluorescence at $425 \mathrm{~m} \mu$ when excited at $355 \mathrm{~m} \mu$. A relative high fluorescence was observed before the formation of the polymeric products (Figs. 1 and 6). With LAHPO RNase did not produce fluorescence up to 2-hr incubation, but incubation beyond $2 \mathrm{hr}$ showed the production of fluorescence. Addition of AsA into the reaction mixture resulted in about $25 \%$ increase in the fluorescence in 2-hr incubation compared to 2-hr incubation without AsA, while BHT was effective in reducing the fluorescence considerably (Fig. 6). Pepsin did not produce fluorescence as significantly as in the case of RNase either with LAHPO or SP although $4 \mathrm{hr}$ incubation with either sample showed a very small amount of fluorescence (Fig. 6). The reaction of trypsin was remarkable with respect to the production of fluorescent products. As can be seen in Fig. 6, SP gave rise to the production of fluorescence from the early stages of incubation while LAHPO did not produce such products up to $4 \mathrm{hr}$.

\section{DISCUSSION}

Damage to proteins by the autoxidized products of lipids is attributed to a complex set of reactions. The radical intermediates produced during the course of lipid peroxidation and degradation of hydroperoxides have been shown to involve in many noxious reactions. Polymerization by the autoxidized lipids have been shown to involve radical intermediates (5) as well as their degraded products $(8)$. The above conclusions have been drawn on the results of lipidprotein peroxidizing systems and as such the reliability of the suggested reactions is open to question. More comfirmatory conclusions can be drawn on the mechanism of protein polymerization by the radical and non-radical products of peroxidized lipids by using purified hydroperoxides (radical initiators) and their degraded products (non-radical products).

It can be concluded from our experimental evidence that the radical intermediates and the non-radical products of peroxidized lipids are both effective in polymerizing RNase. Effects of the radical reaction with respect to the polymerization of RNase in short time reactions could only be detected by using high concentrations of LAHPO, while the rection of SP being time dependent the effects could be observed at low concentrations of SP. Increasing the concentration of SP did not show significant effects in short time reactions (unpublished data).

Within $2 \mathrm{hr}$ of incubation, LAHPO was effective in polymerization of RNase to a considerable extent but it did not cause in the production of fluorescence at $425 \mathrm{~m} \mu$. It has been well established that the fluorescence at $425 \mathrm{~m} \mu$ is due to carbonyl-amine condensation reaction resulting in the formation of conjugated chromophoric Schiff's-base system (8). Thus polymerization of RNase within $2 \mathrm{hr}$ did not involve carbonyl compounds. In contrast, SP did not produce polymers within $2 \mathrm{hr}$ incubation but showed a relative high fluorescence from the beginning of incubation (Fig. 6). The carbonyl-amine reaction takes place 
intramolecularly resulting in fluorescence at $425 \mathrm{~m} \mu$ or intermolecularly effecting cross-linked products having the same fluorescence characteristics (8). Thus the fluorescence at $425 \mathrm{~m} \mu$ shown by RNase when incubated with SP without the formation of polymeric products may be attributed to the intramolecular reaction between SP and the amino groups of RNase. The fluorescence shown by incubating RNase with LAHPO beyond $2 \mathrm{hr}$ may be the result of the interactions of the degraded products of LAHPO which are produced as a result of the reaction of LAHPO with the proteins. From Fig. 2, it can be seen that the incorporation of lipids into the proteins in the formation of polymeric products falls far below the numerical value of 0.5 mole of lipid/mole of protein if lipids are cross-linked with the proteins to form dimers as suggested by DESAI (5).

Considering the reactivity of LAHPO on a radical basis, it can be concluded that the peroxy or the alkoxy radicals formed by the fission of LAHPO initiates a chain reaction resulting in the formation of protein radicals. These protein radicals react together to form polymeric products. This conclusion is in agreement with the observation of RouBAL (3), who suggested that the radical intermediates initiates the production of protein radicals which in turn polymerizes as $\mathrm{P}-(\mathrm{P})_{n}-\mathbf{P}$. This mechanism is further strengthened by the effects of AsA and BHT on the polymer formation of RNase by LAHPO. The pronounced effect of AsA on the polymer formation of RNase by the LAHPO and the relative increase in fluorescence in $2 \mathrm{hr}$ incubation suggests that AsA has increased the rate of production of alkoxy or peroxy radicals. These radicals reacts with the proteins affecting the formation of the protein radicals, while itself being degraded to SP. The antioxidative behavior of BHT further supports the radical mechanism of LAHPO.

The specificity of LAHPO in reacting with enzyme proteins as suggested in our earlier paper (9) is further supported by the results of the present study. Incubating pepsin with LAHPO or SP under the conditions as used in the case of RNase did not produce polymeric products. Only a very small amount of fluorescence was produced even after $4 \mathrm{hr}$ incubation. Although the polymer formation of trypsin could not be detected under the conditions used due to the autolysis of trypsin, fluorescence studies showed similar reactivity of LAHPO or SP as observed in our earlier investigation (9). The SP which showed to be remarkably incorporated into trypsin was significantly effective in producing fluorescent products. LAHPO behaved otherwise in both determinations. Thus the specificity of LAHPO interaction with proteins is clearly established.

Further studies are needed to explain the specificity of LAHPO in protein interaction, but it may be suggested that the differences in the conformational structures in proteins changes the accessibility of the labile amino groups to the radical attack. LOOH (lipid peroxides) should be primarily decomposed to LO* or LOO radicals which are the reactive intermediates. Therefore the groups of proteins responsible for the formation of the radicals from the hydroperoxides 
and the surface exposition of such groups may differ with proteins which may account for the specificity of the radical reaction.

\section{REFERENCES}

1) Lesslaure, W., Wissler, F. C., and Parson, D. F., Biochem. Biophys. Acta, 203, 199 (1970).

2) TAPPel, A. L., Arch. Biochem. Biophys., 54, 266 (1965).

3) Roubal, W. T. and TAppel, A. L., Arch. Biochem. Biophys., 133, 150 (1966).

4) Narayan, K. A. and Kummerow, F. A., J. Am. Oil Chem. Soc., 40, 339 (1963).

5) Desai, I. D. and Tappel, A. L., J. Lipid Research, 4, 204 (1963).

6) Andrews, F., Bjorksten, J., and Trenk, F. B., J. Am. Oil Chem. Soc., 42, 779 (1965).

7) Shin, B. C., Huggins, J. W., and Carraway, K. L., Lipids, 7, 229 (1972).

8) Chio, K. S. and TAPPEL, A. L., Biochemistry, 8, 2827 (1969).

9) Gamage, P. T. and Matsushita, S., Agr. Biol. Chem., 37, 1 (1973).

10) Gamage, P. T., Mori, T. and Matsushita, S., Agr. Biol. Chem., 35, 33 (1971).

11) O’Brien, P. J., Can. J. Biochem., 47, 485 (1969).

12) Henick, A. S., Benca, M. F., and Mitchel, J. H., J. Am. Oil Chem. Soc. 31, 88 (1954).

13) Whitaker, J. R., Anal. Chem., 35, 1950 (1963).

14) Lowry, O. H., Rosebrough, N. J., Farr, A. L., and Randall, R. J., J. Biol. Chem., 193, 265 (1951). 